\title{
Age estimation of indian adults from orthopantomographs
}

\section{Sudhanshu Saxena ${ }^{(a)}$}

(a) Department of Public Health Dentistry, People's College of Dental Sciences and Research Centre, People's group, Bhanpur, Bhopal, Madhya Pradesh, India.

\section{Correponding author:}

Sudhanshu Saxena

Department of Public Health Dentistry, People's College of Dental Sciences and Research Centre, People's group, Bhanpur Karond bypass road

Bhopal - Madhya Pradesh - India

ZIP: 462037

E-mail:dr.sudhanshusaxena@gmail.com

Received for publication on Oct 11, 2010 Accepted for publication on Dec 15, 2010
Abstract: The aim of this study was to develop a method for estimating the chronological age of Indian adults based on the relationship between age and various morphological variables of canine teeth, obtained using orthopantomographs. Orthopantomographs of 120 selected patients were digitized, and radiographic images of the right maxillary canine in each case were processed using a computer aided drafting program. Pulp/ tooth area ratio, pulp/root length ratio, pulp/tooth length ratio, pulp/root width ratio at the cemento-enamel junction level, pulp/root width ratio at midroot level, and pulp/root width ratio at the midpoint between the cemento-enamel junction and the midroot of the canine were calculated by measuring various features on the images. Pearson's correlation, multiple linear regression, one way analysis of variance (ANOVA), and Student's t-test were used for statistical analysis. Regression equations were developed to estimate age from morphological variables. The observed minus the estimated age in the total study sample ranged from -2.2 to +1.5 years, in males from -0.9 to +0.8 years, while in females it was from -1 to +0.8 years. Differences between observed and estimated ages of subjects were not statistically significant. In conclusion there is a linear relationship of pulp/root width ratio at mid-root level and pulp/ tooth area ratio of the right maxillary canine with chronological age in the Indian population. Age of subjects can therefore be estimated with a good degree of accuracy using regression equations.

Descriptors: Forensic Dentistry; Age Determination by Teeth; Adult.

\section{Introduction}

It is often necessary to estimate an individual's age due to certain questions related to legal requirements in paleodemographic research or in a forensic context.

Although several parts of the body can be used for age estimation, the poor condition of the remains in particularly severe crashes or fires in cases of those recently dead; or of moisture and burial conditions in the case of historic subjects, make many parts of the body unusable. For these reasons, the teeth are the part of the body most frequently used for identification and age estimation. ${ }^{1}$

In children, age determination from teeth is a relatively simple, accurate procedure and is based on the stages of development and eruption of teeth. However, in adults it is a challenge to medico-legal science. ${ }^{2}$ Up to now, a multiplicity of methods have been applied to this problem, 
including methods which analyze the various forms of tooth modification such as wear, dentin transparency, tooth cementum annulations, racemization of aspartic acid and apposition of secondary dentin. Some of the methods are very complex and destructive and are therefore not normally used; wear and the apposition of secondary dentin are the currently available nondestructive methods. Tooth wear is influenced by various external factors (masticatory function, type of food, timing and sequence of tooth eruption), tooth form, position of teeth, thickness and hardness of enamel and predisposition to enamel hypoplasia. However, apposition of secondary dentin is a continuing, regular process which is only modified by caries or particular abrasion. Secondary dentin has been studied by sectioning and radiography. ${ }^{1}$

The study of tooth radiographs is a nondestructive and simple process which can be applied to both living and deceased persons, in contrast to other time consuming, expensive, less reliable and destructive methods which may not be acceptable for ethical, religious, cultural or scientific reasons. ${ }^{3}$ Further, procedures such as digitization of panoramic radiographs and computer assisted image analysis avoid the bias inherent in observer subjectivity and improve reliability, accuracy and precision. ${ }^{4}$

Any tooth can be used to assess age. Canine teeth are a good candidate for age estimation because they are often present in old age. They are less likely than other anterior teeth to suffer wear as a result of particular work and are the single-rooted teeth with the largest pulp area and thus are the easiest to analyze. ${ }^{1}$

Based on the above background, this study was conducted to develop a method for estimating the chronological age of Indian adults based on the relationship between age and various morphological variables of canine teeth, obtained using orthopantomographs.

\section{Materials and Methods}

Based on the results of a pilot study, to achieve a $5 \%$ level of significance and $80 \%$ power, a study with a sample size of 120 participants was required, calculated using Power and Precision v. 4 (Biostat
Inc., Englewood, USA). One hundred and twenty orthopantomographs (Planmeca Oy, Helsinki, Finland) from patients of both sexes seen at the People's College of Dental Sciences and Research Centre, Bhopal, Madhya Pradesh state, India, were collected based on the following criteria:

a. Patients aged between 21 to 60 years

b. Fully erupted right maxillary canine

c. Fully formed root of right maxillary canine

d. Right maxillary canine free from any pathology such as caries, periodontitis, abrasion, erosion, fracture or impaction

e. Absence of restoration and endodontic filling of the right maxillary canine

f. Absence of malaligned or rotated right maxillary canine

Orthopantomographs were taken as part of routine treatment that was being rendered to the patient. Participation in the study was voluntary. Relevant data including date of birth and gender were entered into the proforma after obtaining informed consent. Ethical clearance was obtained from the ethical committee of the People's College of Dental Sciences and Research Centre.

\section{Methods}

Orthopantomographs of selected patients were obtained and digitized using an ASTRA 4000U scanner (UMAX Technologies Inc., Dallas, USA). Radiographic images of canines (RIC) were processed using the computer-aided drafting program, Auto CAD 2005 (Autodesk Inc., San Rafael, USA).

Twenty points around the edge of the tooth outline and ten points around the pulp outline of the right maxillary canine were identified. Measurements of the canine tooth area and the pulp area from the radiographic images were then evaluated.

The tooth length, pulp length and root length were measured. The width of the root and pulp at 3 different levels, one at the cemento-enamel junction (CEJ), the second at midroot level and the third at the level of the midpoint between the CEJ and the midroot level were measured. All measurements were carried out by a single observer. To test intraobserver reproducibility, a random sample of thirty 
RIC were re-examined after an interval of one week.

The following morphological variables were calculated from the above measurements:

- $\mathrm{AR}=$ pulp/tooth area ratio

- $\mathrm{p}=$ pulp/root length ratio

- $r=$ pulp/tooth length ratio

- $\mathrm{a}=$ pulp/root width ratio at CEJ level

- $\mathrm{c}=$ pulp/root width ratio at midroot level

- $\mathrm{b}=$ pulp/root width ratio at midpoint level between CEJ level and midroot level

The observed age was calculated by subtracting the date of birth from the date of the radiograph.

Statistical analysis was performed using SPSS v. 17 (SPSS Inc., Chicago, USA). Pearson's correlation coefficients were calculated for the relationship between observed age and predictive variables. A multiple linear regression model for age estimation was developed by selecting those variables which contributed significantly to age estimation. One way analysis of variance (ANOVA) was used to compare differences between observed and estimated age in different age groups. Student's t-test was used to compare the morphological variables of males with those of females and to compare observed age with estimated age. A p value $<0.05$ was considered statistically significant.

\section{Results}

Kappa statistics showed that the intra-examiner agreement score $(\mathrm{k}=0.94)$ was almost perfect.

In the present study, 60 males and 60 females (total 120 subjects) were equally divided into four age groups, i.e. 21-30 years, 31-40 years, 41-50 years, and 51-60 years.

The morphological variables did not show any significant difference between the sexes $(p>0.05)$. Pearson's correlation coefficients between observed age and predictive morphological variables in males, females and in the total sample population were highly significant and inversely correlated for AR (pulp/tooth area ratio) and $\mathrm{c}$ (pulp/root width ratio at midroot level) $(\mathrm{p}<0.001)$.

The subjects' ages were modeled as a linear function of the morphological variables (predictors). A multiple linear regression procedure was therefore applied to optimize this model.

Table 1 shows the regression analysis of the total sample, while Table 2 shows the results in males and Table 3 in females. Among all the morphological variables tested, only AR (pulp/tooth area ratio) and c (pulp/root width ratio at midroot level) showed significant results. Hence, a regression model utilizing AR and c was used (Table 4) which yields the following linear regression formula to estimate chronological age:

- For subjects of unknown gender:

Age $=72.48-203.74(\mathrm{AR})-51.69(\mathrm{c})$

- For male subjects:

Age $=73.33-209.97(\mathrm{AR})-54.06(\mathrm{c})$

- For female subjects:

Age $=72.12-179.12(\mathrm{AR})-68.66(\mathrm{c})$

Table 1 - Regression analysis with all morphological variables (predictors) and age as the dependent variable in the total study sample $(\mathrm{n}=120)$.

\begin{tabular}{c|r|r|r|r}
\hline \multirow{2}{*}{ Model } & \multirow{2}{*}{$\begin{array}{c}\text { Regression } \\
\text { coefficient }\end{array}$} & \multirow{2}{*}{$\begin{array}{c}\text { Standard } \\
\text { error }\end{array}$} & \multicolumn{2}{|c}{ Significance } \\
\cline { 4 - 5 } & & & \multicolumn{1}{|c}{ t value } & \multicolumn{1}{c}{$p$ value } \\
\hline Constant & 71.65 & 0.60 & 120.30 & $<0.001$ \\
\hline AR & -204.52 & 3.78 & -54.16 & $<0.001$ \\
\hline$p$ & 0.09 & 0.44 & 0.21 & 0.833 \\
\hline$r$ & 0.59 & 0.70 & 0.84 & 0.402 \\
\hline$a$ & 0.63 & 0.59 & 1.07 & 0.285 \\
\hline$b$ & 1.48 & 1.02 & 1.46 & 0.148 \\
\hline$c$ & -52.21 & 3.66 & -14.24 & $<0.001$ \\
\hline
\end{tabular}

Dependent variable: Age

Table 2 - Regression analysis with all morphological variables (predictors) and age as the dependent variable in males $(n=60)$.

\begin{tabular}{c|r|c|r|r}
\hline \multirow{2}{*}{ Model } & \multirow{2}{*}{$\begin{array}{c}\text { Regression } \\
\text { coefficient }\end{array}$} & \multirow{2}{*}{$\begin{array}{c}\text { Standard } \\
\text { error }\end{array}$} & \multicolumn{2}{|c}{ Significance } \\
\cline { 4 - 5 } & & & t value & \multicolumn{1}{c}{$p$ value } \\
\hline Constant & 73.05 & 0.67 & 109.13 & $<0.001$ \\
\hline AR & -175.09 & 6.0 & -29.19 & $<0.001$ \\
\hline$p$ & -0.11 & 0.38 & -0.28 & 0.780 \\
\hline$r$ & -0.92 & 0.75 & -1.22 & 0.226 \\
\hline$a$ & -0.95 & 1.41 & -0.67 & 0.504 \\
\hline$b$ & -0.72 & 1.44 & -0.50 & 0.617 \\
\hline$c$ & -70.54 & 4.83 & -14.60 & $<0.001$ \\
\hline
\end{tabular}

Dependent variable: Age 
Table 3 - Regression analysis with all morphological variables (predictors) and age as the dependent variable in females $(n=60)$.

\begin{tabular}{c|r|r|r|r}
\hline \multirow{2}{*}{ Model } & \multirow{2}{*}{$\begin{array}{c}\text { Regression } \\
\text { coefficient }\end{array}$} & \multirow{2}{*}{$\begin{array}{c}\text { Standard } \\
\text { error }\end{array}$} & \multicolumn{2}{|c}{ Significance } \\
\cline { 4 - 5 } & & & \multicolumn{1}{|c}{ t value } & \multicolumn{1}{c}{$p$ value } \\
\hline Constant & 72.54 & 0.59 & 122.52 & $<0.001$ \\
\hline AR & -208.10 & 3.11 & -66.82 & $<0.001$ \\
\hline$p$ & 1.05 & 0.57 & 1.83 & 0.073 \\
\hline$r$ & -0.39 & 0.73 & -0.53 & 0.597 \\
\hline$a$ & 0.49 & 0.42 & 1.17 & 0.247 \\
\hline$b$ & 0.23 & 0.88 & -0.26 & 0.792 \\
\hline$c$ & -56.37 & 3.45 & -16.36 & $<0.001$ \\
\hline
\end{tabular}

Dependent variable: Age

Table 4 - Regression analysis with selected morphological variables (predictors) and age as the dependent variable.

\begin{tabular}{|c|c|c|c|c|c|}
\hline \multirow{2}{*}{ Group } & \multirow{2}{*}{ Model } & \multirow{2}{*}{$\begin{array}{l}\text { Regression } \\
\text { coefficient }\end{array}$} & \multirow{2}{*}{$\begin{array}{c}\text { Standard } \\
\text { error }\end{array}$} & \multicolumn{2}{|c|}{ Significance } \\
\hline & & & & t value & $p$ value \\
\hline \multirow{3}{*}{ 홍 } & Constant & 72.48 & 0.19 & 388.39 & $<0.001$ \\
\hline & $A R$ & -203.74 & 3.71 & -54.93 & $<0.001$ \\
\hline & c & -51.69 & 3.63 & -14.24 & $<0.001$ \\
\hline \multirow{3}{*}{ 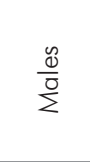 } & Constant & 73.33 & 0.21 & 349.76 & $<0.001$ \\
\hline & $A R$ & -209.97 & 2.99 & -70.24 & $<0.001$ \\
\hline & c & -54.06 & 3.27 & -16.54 & $<0.001$ \\
\hline \multirow{3}{*}{ 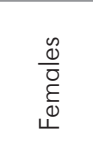 } & Constant & 72.12 & 0.16 & 437.99 & $<0.001$ \\
\hline & AR & -179.12 & 5.00 & -35.83 & $<0.001$ \\
\hline & c & -68.66 & 4.53 & -15.16 & $<0.001$ \\
\hline
\end{tabular}

Dependent variable: Age

The observed minus the estimated age in the total sample population ranged from -2.2 to +1.5 years. There was no significant difference between observed and estimated age for any of the age groups (Table 5). In addition, the differences of observed and estimated age between age groups were also not statistically significant $($ ANOVA value $=2.259$, $\mathrm{p}=0.085)$.

The observed minus the estimated age in males ranged from -0.9 to +0.8 years, while in females it ranged from -1 to +0.8 years. There was no significant difference between observed and estimated age for either males or females (Table 6).
Table 5 - Comparison of observed and estimated age in subjects grouped according to age.

\begin{tabular}{c|r|r|r|c}
\hline \multirow{2}{*}{$\begin{array}{c}\text { Age } \\
\text { groups } \\
\text { (years) }\end{array}$} & \multicolumn{2}{|c|}{ Age in years $($ mean \pm SD) } & \multirow{2}{*}{$\begin{array}{c}\text { t-test } \\
\text { value }\end{array}$} & p value \\
\cline { 2 - 5 } & Observed age & Estimated age & \\
\hline $21-30$ & $24.86 \pm 2.98$ & $24.64 \pm 3.25$ & 0.267 & $0.790(\mathrm{NS})$ \\
\hline $31-40$ & $35.25 \pm 2.73$ & $35.30 \pm 2.64$ & 0.061 & $0.952(\mathrm{NS})$ \\
\hline $41-50$ & $44.60 \pm 3.02$ & $44.46 \pm 3.11$ & 0.171 & $0.865(\mathrm{NS})$ \\
\hline $51-60$ & $55.09 \pm 2.55$ & $54.81 \pm 2.60$ & 0.432 & $0.667(\mathrm{NS})$ \\
\hline Over all & $39.95 \pm 11.58$ & $39.80 \pm 11.56$ & 0.100 & $0.921(\mathrm{NS})$ \\
\hline
\end{tabular}

${ }^{*} \mathrm{NS}=$ Not significant

Table 6 - Comparison of observed and estimated age of subjects according to gender.

\begin{tabular}{c|c|c|c|c}
\hline \multirow{2}{*}{ Gender } & \multicolumn{2}{|c|}{ Age in years (mean \pm SD) } & \multirow{2}{*}{$\begin{array}{c}\text { t-test } \\
\text { value }\end{array}$} & p value \\
\cline { 2 - 5 } & Observed age & Estimated age & & \\
\hline Male & $40.20 \pm 11.15$ & $40.04 \pm 11.13$ & 0.080 & $0.937(\mathrm{NS})$ \\
\hline Female & $39.70 \pm 12.08$ & $39.56 \pm 12.05$ & 0.062 & $0.951(\mathrm{NS})$ \\
\hline Over all & $39.95 \pm 11.58$ & $39.80 \pm 11.56$ & 0.100 & $0.921(\mathrm{NS})$ \\
\hline
\end{tabular}

*NS $=$ Not significant

\section{Discussion}

The results of the present study showed no significant difference between observed and estimated age. Age was estimated using regression equations based on pulp/tooth area ratio and pulp/root width ratio at mid-root level.

In 1925 Bodecker established that the apposition of secondary dentin correlated with age. ${ }^{5}$ In 1995, Kvaal et al. presented a method for age estimation which was based on investigation of periapical radiographs, ${ }^{3}$ while Paewinsky et al. verified the applicability of this method on orthopantomograms. ${ }^{6}$

In 2004 Cameriere et al. found a linear relationship between the pulp/root width ratio at mid-root level, the pulp/tooth area ratio, and chronological age. ${ }^{4}$ This finding was consistent with the findings in present study. Cameriere et al. stated that the ratio between pulp and tooth area correlated best with age. ${ }^{4}$ With this background they developed regression equations for age estimation using the pulp/ tooth area ratios of canines from the maxilla and the mandible separately. ${ }^{1}$

In their study, Babshet et al. found that Cameri- 
ere's formula, based on the Italian population, is not as applicable to the Indian population. ${ }^{7}$ I also found the same result in my pilot study using this formula. These results indicate that racial and cultural factors might play an important role in age estimation. Therefore I decided to develop regression equations for the Indian population. I used both pulp/root width ratio at mid-root level and pulp/tooth area ratio in regression equations to make the equation as close to ideal as possible.

The present study showed no significant influence of gender on age estimation using canine tooth measurements, which was similar to the findings of previous studies..$^{1,4,8}$ Nevertheless I developed separate formulas for males and females to predict age as accurately as achievable.

The present study showed $99.7 \%$ variance and 0.60 standard error of the estimate, when selected variables were used. This result was similar to results of the study conducted by Cameriere et al., who reported $97 \%$ variance with 2.37 years standard error of the estimate. ${ }^{9}$

\section{References}

1. Cameriere R, Ferrante L, Belcastro MG, Bonfiglioli B, Rastelli $\mathrm{E}$, Cingolani M. Age estimation by pulp/tooth ratio in canines by peri-Apical Xrays. J Forensic Sci. 2007 Jan;52(1):166-70.

2. Jain RK, Rai B. Age estimation from permanent molar's attrition of Haryana population. Indian J Forensic Odontol. 2009 Apr;2(2):59-61.

3. Kvaal SI, Kolltveit KM, Thomsen IO, Solheim T. Age estimation of adults from dental radiographs. Forensic Sci Int. 1995 Jul 28;74(3):175-85.

4. Cameriere R, Ferrante L, Cingolani M. Variations in pulp/ tooth area ratio as an indicator of age: a preliminary study. $\mathrm{J}$ Forensic Sci. 2004 Mar;49(2):317-9.

5. Meinl A, Tangl S, Pernicka E, Fenes C, Watzek G. On the applicability of secondary dentin formation to radiological age estimation in young adults. J Forensic Sci. 2007 Mar;52(2):438-41.
Though my results are promising, I cannot generalize them to other populations. Further research should be aimed at analyzing a larger sample, including not only age and gender but also racial and cultural parameters. This method of age estimation cannot be applied to multirooted teeth, as accurate measurements are difficult to perform on these. Similarly, as the curved arch of the jaw is projected on to a flat film, there will always be a certain amount of distortion when measuring the image presented there. ${ }^{8}$ To create a uniform amount of distortion in all the radiographs used I chose a particular tooth, the right maxillary canine.

\section{Conclusion}

Within the limitations of the study it can be concluded that there is a linear relationship of pulp/root width ratio at mid-root level, and pulp/tooth area ratio of the right maxillary canine with chronological age in the Indian population. In unknown subjects age can be estimated using regression equations based on the above mentioned variables.

6. Paewinsky E, Pfeiffer H, Brinkmann B. Quantification of secondary dentine formation from orthopantomograms--a contribution to forensic age estimation methods in adults. Int J Legal Med. 2005 Jan;119(1):27-30.

7. Babshet M, Acharya AB, Naikmasur VG. Age estimation in Indians from pulp/tooth area ratio of mandibular canines. Forensic Sci Int. 2010 Apr 15;197(1-3):125.e1-4. Epub 2010 Jan 27.

8. Singaraju S, Sharada P. Age estimation using pulp/tooth area ratio: a digital image analysis. J Forensic Dent Sci. 2009 May;1(1):37-41.

9. Cameriere R, Cunha E, Sassaroli E, Nuzzolese E, Ferrante L. Age estimation by pulp/tooth area ratio in canines: study of a Portuguese sample to test Cameriere's method. Forensic Sci Int. 2009 Dec 15;193(1-3):128.e1-6. Epub 2009 Oct 24. 